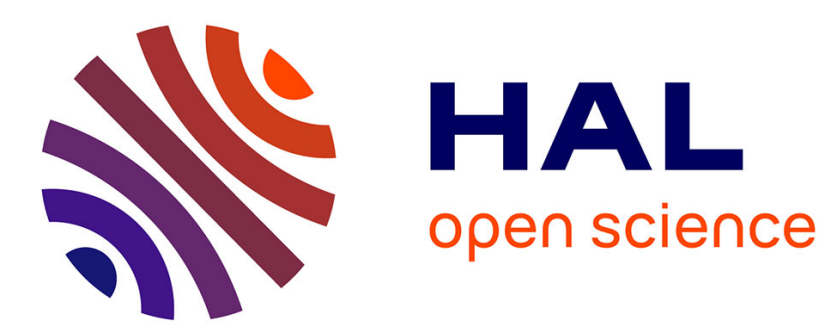

\title{
Rebuttal of "Compatibility of local and global stability conditions for some discrete population models," by S.H. Saker
}

\author{
Eduardo Liz
}

\section{- To cite this version:}

Eduardo Liz. Rebuttal of "Compatibility of local and global stability conditions for some discrete population models," by S.H. Saker. Nonlinear Dynamics, 2010, 61 (4), pp.859-860. 10.1007/s11071010-9692-8 . hal-00578413

\section{HAL Id: hal-00578413 \\ https://hal.science/hal-00578413}

Submitted on 20 Mar 2011

HAL is a multi-disciplinary open access archive for the deposit and dissemination of scientific research documents, whether they are published or not. The documents may come from teaching and research institutions in France or abroad, or from public or private research centers.
L'archive ouverte pluridisciplinaire HAL, est destinée au dépôt et à la diffusion de documents scientifiques de niveau recherche, publiés ou non, émanant des établissements d'enseignement et de recherche français ou étrangers, des laboratoires publics ou privés. 


\title{
Rebuttal of "Compatibility of local and global stability conditions for some discrete population models", by S. H. Saker
}

\author{
Eduardo Liz
}

March 17, 2010

Paper [1] contains two main results (Theorems 2.1 and 2.3), and a corollary (labelled as Theorem 2.2). The author claims that these results are new, and establishes a comparison with some previous papers. The aim of this rebuttal is not only to clarify that this claim is false (that is, these results are not new), but also to show that the proofs in [1] are incorrect.

Regarding the novelty of the results, the reader can check that the statement of Theorem 2.1 in [1] is proved in [2, Theorem 2], and the statement of Theorem 2.3 in [1] was previously demonstrated in [3, Example 2.3]. We notice that Theorem 2.2 in [1] is a direct consequence of both Theorem 2.1 and Theorem 2.3.

Amazingly, paper [3] is included in the list of references of [1], but the author does not recognize in his discussion that Theorem 2.3 was already proven there; rather than this, he choose to compare his result with other papers, that were already cited in [3].

The note [2] is not included in the bibliography of paper [1], but I suspect that Dr. Saker knows the paper. For instance, he uses exactly the same motivation and references as in [2].

Secondly, it should be noticed that the techniques used in the proofs of Theorems 2.1 and 2.3 in [1] are different from the ones employed in $[2,3]$. However, as I show below, Saker's proofs are wrong. To justify my assertion, I focus my discussion on the first result, which establishes a global stability condition for the positive

E. Liz

Departamento de Matemática Aplicada II, E.T.S.E. Telecomunicación, Universidade de Vigo, Campus Marcosende, 36310 Vigo, Spain

Tel.: +34-986 812127

Fax: +34-986 812116

E-mail: eliz@dma.uvigo.es equilibrium of the first-order difference equation

$x_{n+1}=f\left(x_{n}\right), n=0,1, \ldots$

where

$f(x)=\alpha x+\frac{\beta x}{1+x^{\gamma}}$.

Here, $\alpha, \beta, \gamma$ are real constants satisfying $0 \leq \alpha<1<$ $\alpha+\beta, \gamma>0$. Equation (1) has a unique positive equilibrium $\bar{x}$, which is locally asymptotically stable if the following condition holds:

$\gamma<\frac{2 \beta}{(1-\alpha)(\alpha+\beta-1)}$

Theorem 2.1 in [1] states that condition (3) ensures the global asymptotic stability of the positive equilibrium $\bar{x}$, that is, all solutions of (1) with positive initial condition converge to $\bar{x}$. For it, the author claims that the map $V(x)=(x-\bar{x})^{2}$ is a (strict) Lyapunov function for (1). The same idea is used in the proof of Theorem 2.3 .

If one looks closely to the proof of Theorem 2.1 in [1], it becomes apparent that there are some gaps; namely, it is proved that function $\Delta V(x):=V(f(x))-$ $V(x)$ has a local maximum at $x=\bar{x}$, with $\Delta V(\bar{x})=0$, but existence of other possible critical points is not excluded. This gap does really matter. Actually, function $\Delta V$ can possess other local maxima reaching positive values, so in that case $V$ is not a Lyapunov function for (1), in contradiction with the claim in [1].

For example, take $\alpha=1 / 2, \beta=9$, and $\gamma=4$ in (2). It can be easily verified that inequality (3) holds, but $V(x)=(x-\bar{x})^{2}$ is not a Lyapunov function for (1). See Figure 1, where the graph of $\Delta V(x)$ is represented. 


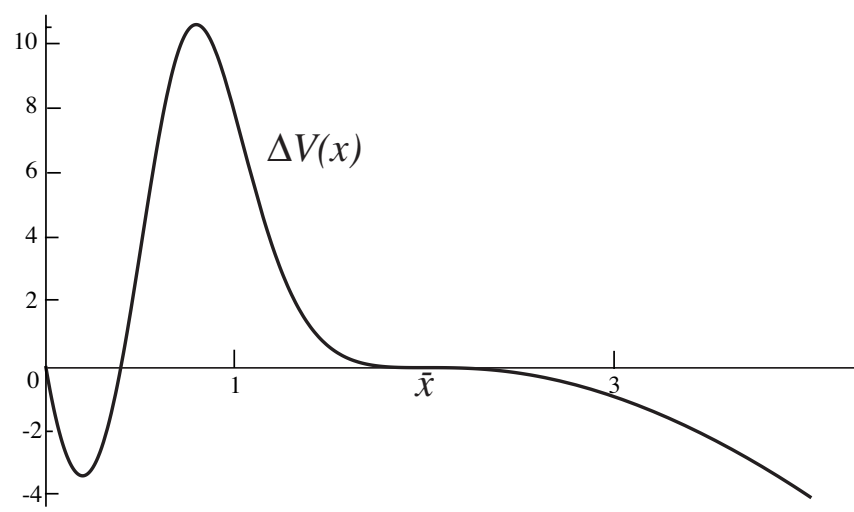

Fig. 1 Graph of the function $\Delta V(x)$. Clearly, it does not reach a global maximum at $x=\bar{x}$.

\section{References}

1. Saker, S. H.: Compatibility of local and global stability conditions for some discrete population models. Nonlinear Dyn. 59, 375-396 (2010).

2. Liz, E.: A sharp global stability result for a discrete population model. J. Math. Anal. Appl. 330, 740-743 (2007).

3. Liz, E.: Local stability implies global stability in some onedimensional discrete single-species models. Discrete Contin. Dyn. Syst., Ser. B 7, 191-199 (2007). 